\title{
Necrolytic Acral Erythema in Seronegative Hepatitis C
}

\author{
Ploychompoo Srisuwanwattana Vasanop Vachiramon \\ Division of Dermatology, Faculty of Medicine, Ramathibodi Hospital, Mahidol University, \\ Bangkok, Thailand
}

\section{Keywords}

Acral involvement $\cdot$ Acrodermatitis enteropathica $\cdot$ Hepatitis C - Glucagonoma $\cdot$ Necrolytic acral erythema Pellagra

\begin{abstract}
Necrolytic acral erythema (NAE) is a distinctive skin disorder. The exact cause and pathogenesis is still unclear. Most studies report an association of NAE with hepatitis C virus (HCV) infection. We report a 64-year-old woman who presented with chronic mildly pruritic brownish to erythematous rashes on both lateral malleoli for 7 months. The clinical and histopathological findings were compatible with NAE. However, the serologic marker for HCV was negative.

(C) 2017 The Author(s)

Published by S. Karger AG, Basel
\end{abstract}

\section{Case Report}

A 64-year-old woman developed mildly pruritic brownish to erythematous rashes on both lateral malleoli for 7 months. She had been diagnosed with lichen simplex chronicus and treated with several types of topical steroids, namely $0.05 \%$ clobetasol propionate ointment and triamcinolone acetonide $10 \mathrm{mg} / \mathrm{mL}$ injection, with minimal improvement. There was no history of significant weight loss or trauma on the affected area. She was otherwise healthy. Physical examination revealed bilateral well-defined brownish hyperkeratot- 
ic plaques with an erythematous rim located on both lateral malleoli (Fig. 1). The scalp and nails were normal. Other physical examinations were unremarkable.

A 4-mm punch biopsy was performed on the left malleolus for routine histological examination. The finding revealed papillated psoriasiform epidermal hyperplasia, compact hyperkeratosis, and mounds of parakeratosis with neutrophils. There were pale and vacuolated keratinocytes in the superficial epidermal layer and scattered necrotic keratinocytes. The granular layer was absent. Dense inflammatory cell infiltrate was composed mainly of lymphocytes. Extravasated erythrocytes with dilated capillaries in the papillary dermis were also observed (Fig. 2, Fig. 3). The histological findings were consistent with necrolytic erythema.

Laboratory finding including anti-hepatitis $\mathrm{C}$ virus (HCV) as well as hepatitis B surface antigen and antibody were negative. Her fasting blood sugar was $107 \mathrm{mg} / \mathrm{dL}$ and her plasma zinc level was $81 \mu \mathrm{g} / \mathrm{dL}$ (normal 70-120 $\mu \mathrm{g} / \mathrm{dL}$ ).

The patient was treated with oral zinc sulfate $220 \mathrm{mg} /$ day, doxepin $25 \mathrm{mg} /$ day, and combined $0.05 \%$ betamethasone dipropionate/3\% salicylic acid ointment twice a day for 1 month. There was no clinical improvement with this regimen, hence the zinc sulfate dose was increased to $440 \mathrm{mg} /$ day, with partial improvement.

\section{Discussion}

Necrolytic acral erythema (NAE) was first described in 1996 by el Darouti and Abu el Ela [1]. It is almost exclusively associated with HCV. However, some cases of NAE have been reported in the absence of HCV infection [2-6]. There was 1 report of NAE following hepatitis $B$ virus vaccination [7]. Its pathogenesis is still unknown. However, it is thought to be related to zinc dysregulation, which can occur as a result of HCV-induced metabolic alteration [8]. NAE is associated with decreased zinc levels in both the serum and the skin [9]. Characteristic features of NAE include sharply marginated scaly erythematous to hyperpigmented plaques predominately on lower extremities [10]. The most common NAE locations are the feet, follow by the lower legs, knees, thighs, genitalia, buttocks, and abdomen. Involvement of the upper extremities is generally mild and limited. The head and neck, palms, soles, nails, and mucous membrane are usually spared [10]. NAE manifests with several stages of involvement. In the initial stage, patients present with scaly erythematous papules or plaques which are deep red to violaceous at the center. Sharply demarcated scaly erythematous to violaceous lichenified plaques can be found in fully developed lesions. Superficial epidermal necrosis is occasionally observed over the dusky portions of the lesion. The pruritic plaque may remain unchanged for months. In the late stage, the lesions become progressively thinner, with some crusting and erosion. NAE is a chronic relapsing and remitting disease, and spontaneous exacerbation can be expected [10].

The differential diagnosis of NAE includes chronic eczema, psoriasis, necrolytic migratory erythema, acrodermatitis enteropathica, and pellagra. This can be differentiated by clinical presentation or histological and laboratory examination.

The histological findings are similar to those of necrolytic erythema characterized by initially acanthosis, epidermal spongiosis, and superficial perivascular dermatitis. Fully developed NAE exhibits psoriasiform hyperplasia and prominent papillomatosis with parakeratosis, subcorneal pustules, epidermal pallor, and necrotic keratinocytes. Confluent necrosis of the keratinocytes in the upper parts of the epidermis may lead to cleft formation. Vascular ectasia, papillary dermal inflammation, and pigment incontinence are also seen [11]. The 
presence of foci of epidermal dyskeratosis and pale keratinocytes helps to differentiated NAE from psoriasis.

Our patient's histological findings were consistent with necrolytic erythema. She had negative serology for HCV infection and a normal plasma zinc level. However, we did not evaluate glucagon, niacin, and biotin levels due to limitation in laboratory processing. Dermatitis of niacin deficiency usually presents in photoexposed areas and may be accompanied by diarrhea and dementia. However, these features were lacking in our patient. She denied any history of weight loss and was generally well; her fasting blood sugar level was within the normal range. Therefore, glucagonoma characterized by glucagon overproduction was less likely. Acquired zinc deficiency, which manifests as eczematous rash preferentially on acral and periorificial sites, is indistinguishable from NAE histologically. Given the normal zinc level, acquired zinc deficiency was the less likely diagnosis in this patient.

The treatment of NAE is difficult, as it is frequently resistant to most topical and systemic agents. Available treatment options are mainly reported in case reports or small case series. Complete or partial resolution has been demonstrated in HCV-associated NAE with interferon alpha-2b and/or ribavirin [12]. Topical corticosteroids result in transient improvement. Systemic corticosteroids showed inconsistent benefit, ranging from no response to complete resolution [12]. The benefit of intralesional triamcinolone acetonide could not be proven. Oral zinc supplementation at a dose of $220 \mathrm{mg}$ twice a day showed a variable response rate, from no response at all to near-complete response [12]. Improvement of NAE after zinc supplementation has been reported in patients with both low and normal zinc levels [12]. Topical tacrolimus together with the combination of zinc, vitamin B1, and vitamin B6 has offered complete resolution in some reports [12, 13].

We present an unusual case of NAE without HCV infection. Although it is rarely reported, NAE should be included as a differential diagnosis in patients presenting with chronic lichenified plaque on the lower extremities.

\section{Statement of Ethics}

The patient gave written informed consent.

\section{Disclosure Statement}

The authors declare no conflicts of interest.

\section{References}

1 el Darouti M, Abu el Ela M: Necrolytic acral erythema: a cutaneous marker of viral hepatitis C. Int J Dermatol 1996;35:252-256.

2 Liu A, Erickson CP, Cockerell CJ, Hsu S: Necrolytic acral erythema: a case not associated with hepatitis C infection. Dermatol Online J 2008;14:10.

-3 Wu YH, Tu ME, Lee CS, Lin YC: Necrolytic acral erythema without hepatitis C infection. J Cutan Pathol 2009;36:355-358.

-4 Nikam BP: Necrolytic acral erythema seronegative for hepatitis C virus - two cases from India treated with oral zinc. Int J Dermatol 2009;48:1096-1099.

5 Panda S, Lahiri K: Seronegative necrolytic acral erythema: a distinct clinical subset? Indian J Dermatol 2010;55:259-261. 


\section{Case Reports in Dermatology}

6 Das A, Kumar P, Gharami RC: Necrolytic acral erythema in the absence of hepatitis C virus infection. Indian J Dermatol 2016;61:96-99.

7 Pernet C, Guillot B, Araka O, Dereure 0, Bessis D: Necrolytic acral erythema following hepatitis B vaccination. Br J Dermatol 2014;171:1255-1256.

$>8$ Najarian DJ, Lefkowitz I, Balfour E, Pappert AS, Rao BK: Zinc deficiency associated with necrolytic acral erythema. J Am Acad Dermatol 2006;55(5 suppl):S108-S110.

-9 Moneib HA, Salem SA, Darwish MM: Evaluation of zinc level in skin of patients with necrolytic acral erythema. Br J Dermatol 2010;163:476-480.

-10 Abdallah MA, Ghozzi MY, Monib HA, Hafez AM, Hiatt KM, Smoller BR, Horn TD: Necrolytic acral erythema: a cutaneous sign of hepatitis C virus infection. J Am Acad Dermatol 2005;53:247-251.

-11 Abdallah MA, Ghozzi MY, Monib HA, Hafez AM, Hiatt KM, Smoller BR, Horn TD: Histological study of necrolytic acral erythema. J Ark Med Soc 2004;100:354-355.

12 Tabibian JH, Gerstenblith MR, Tedford RJ, Junkins-Hopkins JM, Abuav R: Necrolytic acral erythema as a cutaneous marker of hepatitis C: report of two cases and review. Dig Dis Sci 2010;55:2735-2743.

13 Manzur A, Siddiqui AH: Necrolytic acral erythema: successful treatment with topical tacrolimus ointment. Int J Dermatol 2008;47:1073-1075.

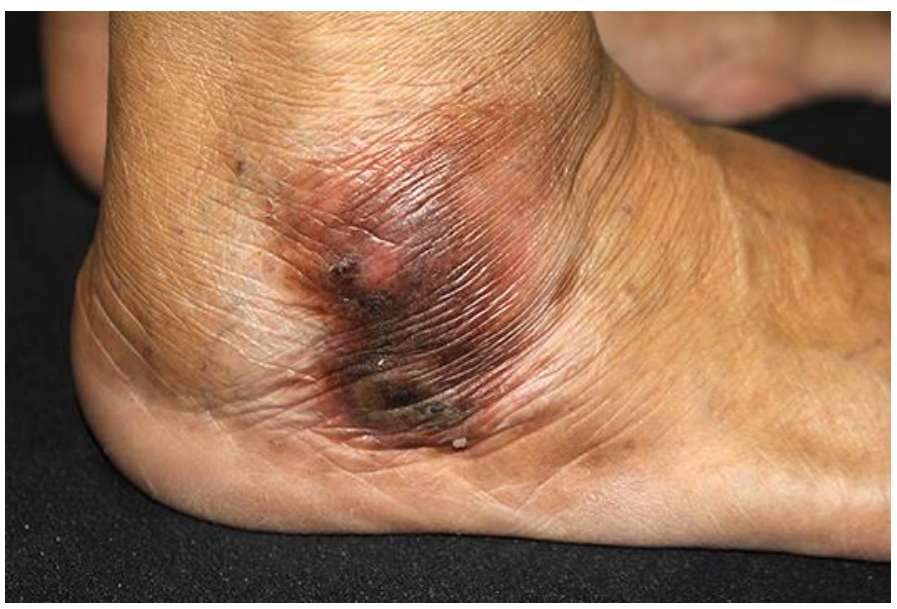

Fig. 1. Well-defined brownish hyperkeratotic plaque with an erythematous rim located on the right lateral malleolus. 


\section{Case Reports in Dermatology}

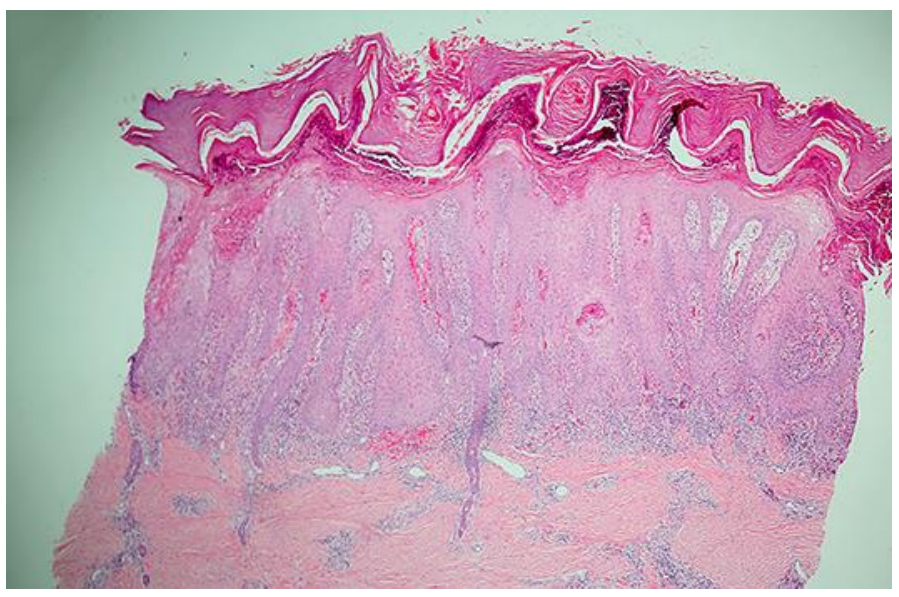

Fig. 2. Histopathological findings revealed papillated psoriasiform epidermal hyperplasia, compact hyperkeratosis, and mounds of parakeratosis with neutrophils. There was absence of a granular layer, with pale and vacuolated keratinocytes in the superficial epidermal layer and scattered necrotic keratinocytes. Hematoxylin-eosin. Original magnification $\times 100$.

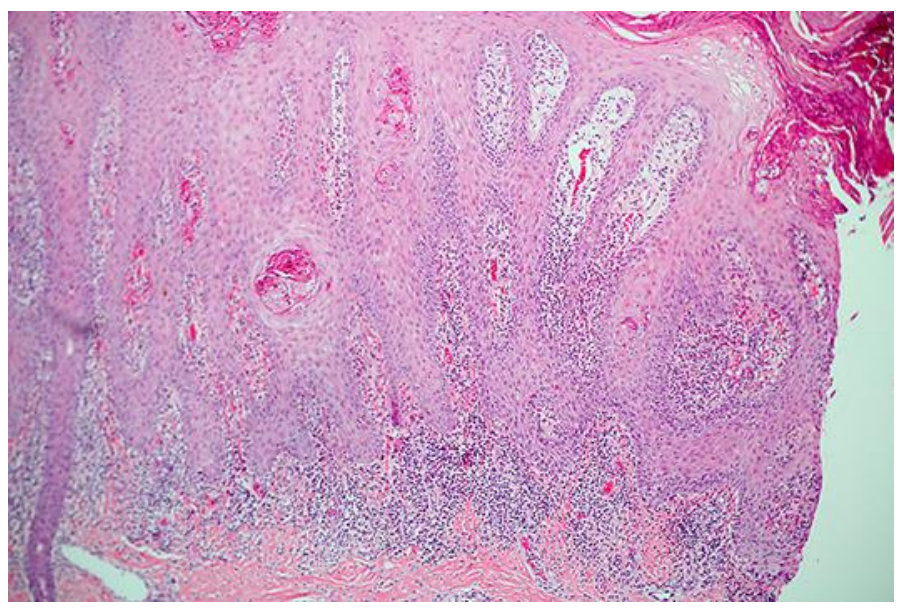

Fig. 3. Dense inflammatory cell infiltrate of mainly lymphocytes and extravasated erythrocytes, with dilated capillaries in the papillary dermis. Hematoxylin-eosin. Original magnification $\times 400$. 